\title{
Comparative genomics of Helicobacter pylori isolates recovered from ulcer disease patients in England
} Farhana Kauser $^{\dagger 1}$, M Abid Hussain ${ }^{\dagger 1}$, Irshad Ahmed ${ }^{3}$, Sriramula Srinivas ${ }^{1}$, S Manjulata Devi ${ }^{1}$, Ahmed A Majeed ${ }^{1}$, K Rajender Rao ${ }^{1}$, Aleem A Khan ${ }^{2,3}$, Leonardo A Sechi ${ }^{2,4}$ and Niyaz Ahmed*1,2

\author{
Address: ${ }^{1}$ Pathogen Evolution Group, Laboratory of Molecular and Cell Biology, Centre for DNA Fingerprinting and Diagnostics (CDFD), \\ Hyderabad, India, ${ }^{2}$ ISOGEM Working Group on Genetics of Helicobacters [International Society for Genomic and Evolutionary Microbiology \\ (ISOGEM)], Hyderabad, India, ${ }^{3}$ Deccan Medical College and Allied Hospitals, Hyderabad, India and ${ }^{4}$ Department of Biomedical Sciences, \\ University of Sassari, Sassari, Italy \\ Email: Farhana Kauser - farhana@cdfd.org.in; M Abid Hussain - abid@cdfd.org.in; Irshad Ahmed - sirfirshadahmed@gmail.com; \\ Sriramula Srinivas - srinivas@cdfd.org.in; S Manjulata Devi - manju@cdfd.org.in; Ahmed A Majeed - ahmed@cdfd.org.in; K \\ Rajender Rao - rajender@cdfd.org.in; Aleem A Khan - aleem_a_khan@rediffmail.com; Leonardo A Sechi - sechila@uniss.it; \\ Niyaz Ahmed* - niyaz@cdfd.org.in \\ * Corresponding author †Equal contributors
}

Published: 25 May 2005

BMC Microbiology 2005, 5:32 doi:10.1186/147I-2180-5-32
Received: 22 February 2005

Accepted: 25 May 2005

This article is available from: http://www.biomedcentral.com/l47/-2/80/5/32

(c) 2005 Kauser et al; licensee BioMed Central Ltd.

This is an Open Access article distributed under the terms of the Creative Commons Attribution License (http://creativecommons.org/licenses/by/2.0), which permits unrestricted use, distribution, and reproduction in any medium, provided the original work is properly cited.

\begin{abstract}
Background: Genomic diversity of $H$. pylori from many different human populations is largely unknown. We compared genomes of $65 \mathrm{H}$. pylori strains from Nottingham, England. Molecular analysis was carried out to identify rearrangements within and outside the cag-pathogenicity-island (cag PAI) and DNA sequence divergence in candidate genes. Phylogenetic analysis was carried out based on various high-resolution genotyping techniques.

Results: Analyses of virulence genes (cagT, cagE, cagA, vacA, iceA, oipA and babB) revealed that $H$. pylori strains from England are genetically distinct from strains obtained from other countries. The toxigenic vacA s $\mathrm{Im} /$ genotype was found to be less common and the plasticity region cluster was found to be disrupted in all the isolates. English isolates showed a predominance of iceAl alleles and a functional proinflammatory oipA gene. The English $H$. pylori gene pool revealed several Asian/ oriental features. This included the predominance of cagA - glr (cagA right junction) motif types III and II (up to 42\%), presence of vacA mlc alleles and phylogenetic affinity towards East Asian I Amerindian gene pools based on fluorescent amplified fragment length polymorphism (FAFLP) analysis and $g / m M$ sequence analysis.

Conclusion: Overall, our results demonstrated genetic affinities of $H$. pylori in England with both European and the Asian gene pools and some distinctive genetic features of virulence genes that may have evolved in this important European population.
\end{abstract}

\section{Background}

Infection of the gastric mucosa with $H$. pylori results in a number of disease outcomes including gastritis, which precedes the development of peptic ulcer disease, gastric cancer and lymphomas of the MALT [1-3]. These diseases caused by $H$. pylori and their prevalence rates differ in 
different geographic countries and only a subset (10\%) [4] of infected patients develop one of them. This raises the question as to why $H$. pylori causes disease in a few individuals, but not in the great majority [5].

Many studies have demonstrated the involvement of bacterial virulence factors, host genetics and environmental factors in contributing to the development of disease. Bacterial virulence factors include proteins mediating establishment/colonization, persistence of infection and finally long-term damage to the host [6]. The cag pathogenicity-island (cag PAI) is the most noteworthy among these factors. PCR analyses have suggested that this island is not intact in many strains across the world [7] and the presence of an intact PAI although not always $[8,9]$ is indicative of a more severe outcome [10]. The expression of various products encoded in the cag PAI is known to be involved in inducing inflammation, ulceration and carcinogenesis [11]. However, the cagA is expressed by the majority of $H$. pylori strains, irrespective of the geographic origin and clinical diagnosis [12].

The vacuolating cytotoxin antigen (VacA) is another virulence factor that is considered to constitute an increased risk for development of peptic ulcers and gastric cancer $[13,14]$. Allelic variations in the vacA gene are found in the signal $(\mathrm{s} 1, \mathrm{~s} 2)$ and the middle region $(\mathrm{m} 1 \mathrm{a}, \mathrm{m} 1 \mathrm{~b}, \mathrm{~m} 2)$ and the $\mathrm{s} 1$ type is associated with ulcer disease $[14,15]$.

More pronounced inflammation is associated with strains, which express the outer membrane protein OipA. OipA induces IL-8 secretion by epithelial cells. Active OipA protein production may be 'on' or 'off depending on the number of CT repeats in the signal sequence of the oipA gene (HP0638). H. pylori strains may also be grouped geographically based on oipA sequence pattern [16]. Specific adhesins viz., babA and $b a b \mathrm{~B}$ mediate the adherence of the bacterium to specific human blood group Lewis antigens and are associated with various disease outcomes [17]. Similarly, a putative E. coli restriction enzyme NlaIII homologue, the iceA gene in $H$. pylori, which is activated on contact with the epithelium, is also shown to induce high levels of IL-8 [18].

Accordingly, strains with OipA 'on' status, active forms of ice A and babA [18] and particularly strains which are cagA + and vacA s1 have been shown to cause a more severe outcome $[14,15,19]$, though not in all cases [20].

Many studies have pointed out a bio-geographical variation in virulence factors; for example, the sequences of vacA and cagA differ in strains from the United States and Europe from those in China and Japan [21]. Also, the prevalence and type of $H$. pylori infection varies with a very high rate of occurrence (up to 70\%) in Asia and the Mid- dle East [22], in contrast to only $30-50 \%$ in Europe and the United States [23]. Further, the infection is minimal in children in the west while in the rest of the world it affects both young and the old. Active infection with $H$. pylori was seen in about 7.5 million people in the general population of England and Wales. This although varied from one region to the other with the highest rates recorded in London [24]. Thus H. pylori remains an important infection in the UK.

H. pylori population has been described as highly recombining, and therefore exhibits enormous strain diversity, part of it may be due to the presence of the plasticity zones [25]. Since this organism has also been shown to be transmitted within families, a greater number of epidemiological studies reveal that these strains not only show similar genotypic profiles when obtained from related patients but also show common profiles within isolates from specific countries [26]. Phylogeographic affinities were pronounced in case of European strains based on the multi locus sequence typing of seven housekeeping genes where the European strains and the Asian strains shared an ancestral relationship [27]. This observation was also recorded in other studies based on the evolutionarily conserved ERIC sequences that indicated close associations between the Irish, Spanish and the European strains and also clustering of the English strains with a few Asian strains [26]. However, the number of English strains used in that study was very small. It is noteworthy in this respect that comprehensive phylogenetic analyses in case of English strains have been rarely performed.

In this study, we aimed at a comprehensive assessment of the prevalent genetic structure of $H$. pylori strains infecting the English population in Nottingham, which is centrally located in the United Kingdom. The strains were analyzed to study a total of 45 different parameters pertaining to 28 informative loci including the virulence factors cagA, oipA, ice $\mathrm{A}$ and vacA in addition to other genes of the cag PAI and the motifs downstream to it. Composition of the plasticity region cluster including the putative gastritis (JHP0986) and gastric cancer (JHP0947) associated markers were also studied [25]. Phylogenetic analyses were performed using FAFLP markers, nucleotide sequences of the cagA, $b a b \mathrm{~B}$ and the glm M genes and the repetitive sequences interspersed in the H. pylori genome (ERIC and REP). According to our observations, phylogenetic placement of English strains shows affinities with East Asian and Amerindian strains.

\section{Results}

Details of all the genotyping and phylogenetic analyses have been depicted in Figures 1 and 2 and are summarized in Additional file 1. 


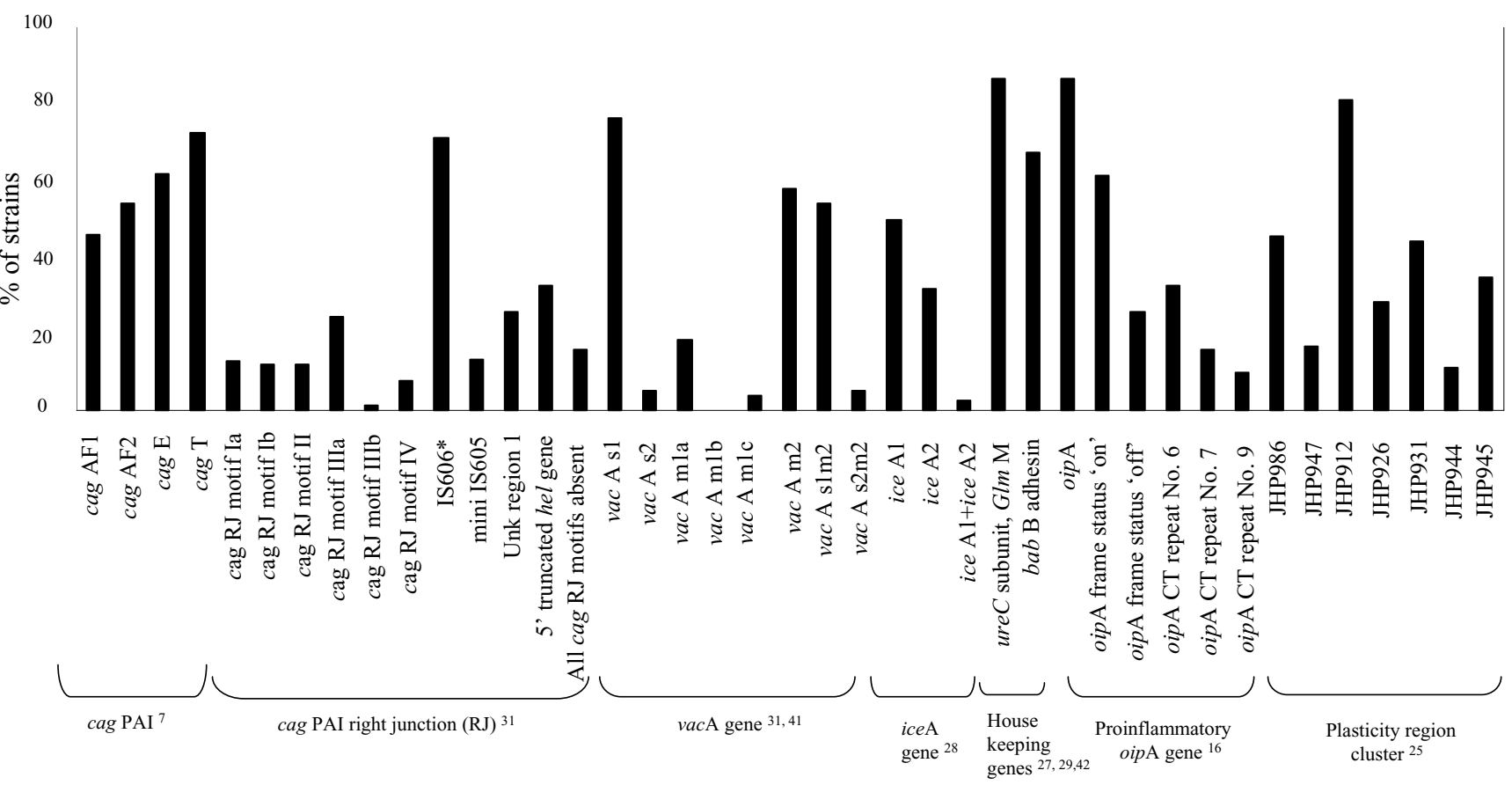

\section{Figure I}

Diagram showing the percent distribution of different genetic loci in the English isolates. The presence of the cag PAI with the motifs on its right end, the vacA and iceA genotypes and the presence of the glmM and babB house keeping genes and characteristics of the virulence gene oipA and the genes included in the plasticity region cluster are shown. The distribution was determined by PCR using primer sequences from the reference articles denoted by the number in superscript.

\section{Macroscale analysis of the cag-PAI and the downstream motifs}

The status of cag A gene was assessed by using primers specific to sequences at both the 5 ' end and the 3 ' ends. PCRs for the $5^{\prime}$ end were positive in 41 strains $(62.1 \%)$, whereas only 35 strains (53\%) were PCR positive for the cag 3 ' end. Twenty-one strains $(31.8 \%)$ had both the ends detected by PCR indicating therefore the possible presence of a complete gene.

Of the ten strains PCR negative for both cagA ends, the oipA gene frame status was "on" for 8 of them. Hence we showed no association between the presence of the cagA gene and the frame status of oipA. Only two strains out of the 10 completely PCR negative for cagA did not have any motif type on the right end of the gene PCR amplified.

The most frequently detected gene by PCR in UK strains was cagT ( $83.3 \%)$ followed by cagE (71.2\%).

Upon analysis of the extreme right junction of the cag PAI (region extending from the cag A 3' region to the glr gene), 54 strains out of 66 had either the type IIIa motif (28.8\%) or the type I ( Ia/Ib) motif (28.8\%). The type IIIb motif was observed in a single isolate (N3), while $13.6 \%$ strains displayed the type II motif. The type IV motif was amplified in only $9 \%$ of the strains and among the three strains recovered from patients of Indo - Pakistani origin, N105 showed a type I a signature, while N115 showed type II motif. The type III motif was also observed for strains from patients of Chinese (N 99) and Russian (N90) ethnicities settled in UK.

The frame status of the oipA gene was 'off' in 8 of the 12 strains that did not have successful amplification of any motif types on the right end of the cag PAI and between the 3 ' end of the glr gene.

The sequence of the $250 \mathrm{bp}$ product amplified from the 3 ' end of the cagA gene was determined for 16 English strains. Phylogenetic analyses of these sequences in comparison with others from Holland $(\mathrm{n}=1)$, East Asia $(\mathrm{n}=$ $4)$, India $(\mathrm{n}=2)$, Bangladesh $(\mathrm{n}=2)$, South America (Peru, $\mathrm{n}=2$ and Guatemala, $\mathrm{n}=2)$, South Africa $(\mathrm{n}=1)$ and Gambia $(\mathrm{n}=2)$ ) (Figure $2 \mathrm{E})$ revealed that the Asian strains carried a unique cagA gene sequence and formed a 
A
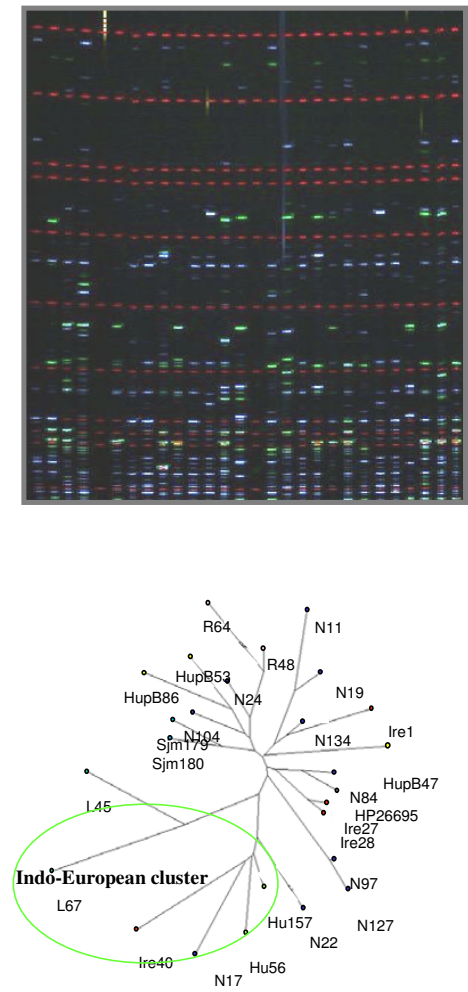

$\mathrm{C}$

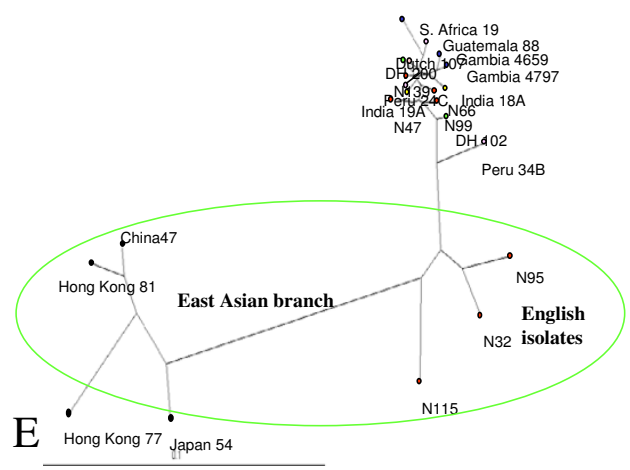

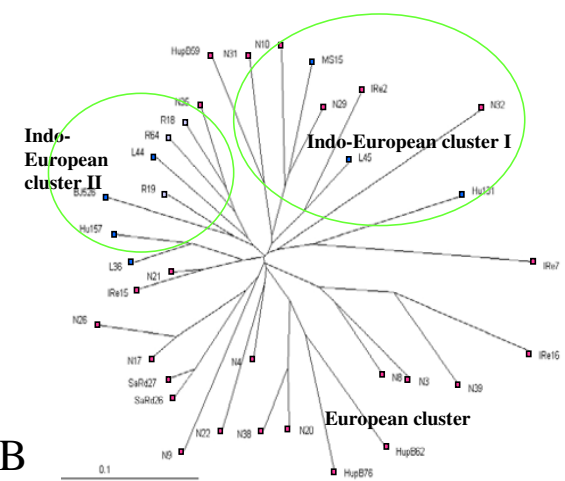
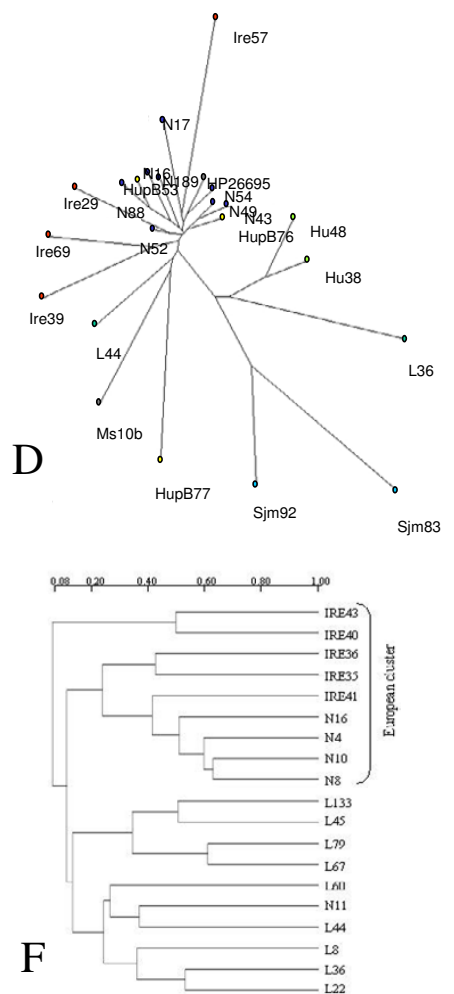

\section{Figure 2}

(A) shows a gel image of representative FAFLP patterns of English $H$. pylori strains with the bands in red indicating the internal lane standards (Genescan Rox 500). (B) Representative phylogenetic tree indicating genetic relationships between English $H$. pylori strains $(n=16)$ and those from other world populations (HupB, $n=3 ;$ Ire, $n=3$; Italy (Sard), n= 2; R = 2; E. Asia $(H u), n$ $=2$; India (L, MS, BJ), $n=5$ ) based on the FAFLP profiles generated for the strains from different countries (described in the materials and methods section). The neighbour joining network tree created based on the level of similarity between the amplitypes shows that European strains form a distinct cluster although two other clusters showing associations with the Indian strains are also seen. (C) Cluster analysis of the $296 \mathrm{bp}$ g/mM was generated with 10 English strains, 2 strains each from India (L), E. Asia (Hu), Peru (Sjm) and S. Africa (R). 4 each from Ire and HupB and the sequenced HP26695. The rounded circle here shows the grouping of English islolate (N 17) with the Indian (L) and E. Asian (Hu) strains. (D) Tree constructed from the babB gene products from different strains ( $N, n=8$; Ire, $n=4$; HupB and MS, L, $n=3$ respectively, 2 each of Hu and Sjm with HP26695). (E) Genetic relationships of the English strains based on the 250 bp sequence of the 5 'end of the cagA gene (England, $n=7$; East Asia, $n=4 ; S$. Africa, $n=1 ;$ W. Africa, $n=2 ; S$. America, $n=2$; central America, $n=I ;$ India, $n=2 ;$ Bangladesh, $\mathrm{n}=2$ and Holland, $\mathrm{n}=\mathrm{I}$ ). A few strains from Nottingham showed sequence similarity with the Asian strains as indicated by the circles in green. $(F)$ Phylogenetic tree based on the REP fingerprinting patterns generated by the English strains $(n=5)$ in comparison with 5 strains from Ire and 6 from India (L). 
segregated cluster. Strains from Africa clustered close to the Indian ones whereas English strains showed no specific clustering.

\section{vacA and ice $A$ statuses of the isolates}

$87.8 \%$ of the strains possessed the toxigenic type s 1 vacA allele while the less toxigenic s2 allele was detected in $6 \%$ strains. The vacA $\mathrm{m} 2$ genotype was present in $66.6 \%$ strains and only $21.2 \%$ strains had the m 1 a genotype. The m1c subtype found in strains from India [28] was observed in 3 strains and none of the strains had a type $\mathrm{m} 1 \mathrm{~b}$ vacA allele. Therefore, the $\mathrm{s} 1 \mathrm{~m} 2$ type of vacA was most commonly (66.6\%) found in these English strains. Only 38 of the 58 strains (65.5\%) with vacA s1 allelic subtype had the oipA gene in frame.

The iceA1 allele was present in 38 strains (57\%) whereas the iceA2 allele was found in 24 strains (36.3\%). Only two strains were positive for both the alleles (N22, N105). The likely explanation is that these "strains" were in fact mixture of two strains.

\section{Status of the Proinflammatory protein oipA gene (HP0638)}

Strains from UK mostly had the oipA frame status 'on' (70.5\%) with the CT dinucleotides repeated 6 times in $37.7 \%$ strains. This was followed by the repeat number of 7 observed in $18 \%$ strains and 9 in $11.5 \%$ strains. $10 \mathrm{CT}$ repeats were found in a single isolate (N52) and a single repeat was shown in three strains. These results and those for other loci studied are shown in the bar diagram [Figure $1]$.

\section{Inventory of the plasticity region ORFs in English strains} The ORF HP986 (referred to as the gastritis associated marker) [25] was PCR amplified in 31 strains (52.5\%), while the gastric cancer associated ORF JHP947 [25], was amplified in only 10 strains (19.2\%). Other ORFs from this region that were amplified included JHP912, which was seen in 93.5\% strains. The ORF JHP926 was amplified in $32.6 \%$ of the strains while a J99 specific ORF JHP931 thought to be involved in DNA replication [25] was found in 51.1\% strains. ORFs JHP944 and JHP945 were amplified in $13 \%$ and $40 \%$ strains respectively. None of the strains showed any specific pattern of ORFs within the plasticity region.

\section{Phylogenetic placement and affinities with other genogroups}

The housekeeping gene, $g \operatorname{lm} \mathrm{M}$, was present in all the strains (100\%) and the adhesin babB was amplified in 51 strains $(77.27 \%)$. The $b a b \mathrm{~B}$ gene has been a marker of choice for tracing lineage in $H$. pylori and recent studies employing this gene have postulated $H$. pylori 's association with its human host to be approximately 11,000 years old $[27,29]$. Hence phylogenies [Figure $2 \mathrm{C}-\mathrm{glm} \mathrm{M}$ tree and $2 \mathrm{D}-b a b \mathrm{~B}$ tree] were generated based on the sequences of these genes in representative strains. These phylogenies revealed that strains from England clustered with other European strains (Ireland-Ire and SpainHupB), while some affinities between them and Peruvian strains could also be noticed. Individual branches representing geographically specific $\operatorname{glm} \mathrm{M}$ sequences were observed for India (MS, L), Japan (Hu), and Africa (R).

FAFLP patterns of English strains revealed about 130 fragments in the size range of 50-500 bp when the genomic DNA was digested with enzymes MseI+0/EcoRI+A. A binary table indicating the presence or absence of a particular amplicon in each strain was scored and these values were used to assess the genetic relatedness within English (abbreviated N) and with other European strains including those from Sardinia (SarD), Spain (HupB) and Ireland (Ire). These strains clustered in one group labeled in the figure as the European cluster. Another cluster obtained was the one which represented contribution from Asian- European gene pool and included strains from India (L, BJ \& MS), Japan (Hu), Africa (R) and others from Europe (HupB, Ire, N) [Figure 2B].

A similar trend was observed with other fingerprinting techniques employing the Enterobacterial Repetitive Intergenic Consensus sequences (ERIC) and the Repetitive Extragenic Palindrome (REP) sequences. Based on the amplification patterns of genomic DNA between the REP sequences, the English strains grouped with the Irish ones in a European cluster and a segregated cluster constituting all Indian strains from Ladakh and a single strain from England (N114) was obtained [Figure 2F]. ERIC phylogeny for this set of strains in comparison with other strains from different world populations as reported earlier [26] indicated that these strains clustered closely with either the Spanish and Irish strains and more distantly with the Indian and African strains.

\section{Discussion}

Evolution of infectious microorganisms is a consequence of the genetic polymorphisms they accumulate, which in turn is the result of the long term selection pressure exerted by the host immune system in case of chronic infection as well as the environment $[9,30]$. This is more pronounced in case of bacteria like $H$. pylori that cause multi decade long infections, wherein an acquiescent requirement to constantly keep their genomic content recasting is crucial. In $H$. pylori this concern is resolved by the use of restriction - modification systems and regulation at gene level by nucleotide substitution, insertion and deletion events [31]. Further, the presence of insertion elements, plasticity regions and the pathogenicity islands contribute considerably to its genetic diversity. 
We attempted to analyze genetic variation and structure of H. pylori populations infecting the native people of England. The UK today is more culturally diverse than ever before with the majority of the UK population being ethnic Europeans (92 \%). The remaining 4.6 million (or 7.9 $\%$ ) people represent other ethnic groups. South Asians are the largest of these groups, followed by Caribbean and Black Africans [32]. Such a multiethnic presence creates an interesting genetic conundrum when we attempt to analyze incidence and healthcare-impact of any pathogen that biases itself with respect to the host genetic makeup. Also, associations of the disease outcome with the virulence factors has thus far been enigmatic and since there were no comprehensive studies involving multiple loci for genotype-phenotype assessments, the current study was envisaged in combination to generate base line data relevant in molecular epidemiology of virulent strains in England.

The cag PAI is a major virulence determinant in $H$. pylori and strains lacking this island are akin to commensals rather than pathogens [1]. Reports suggest that the presence of a complete set of genes within the cag PAI ensures a 5-fold increased severity of disease outcome than the intermediate PAI [10]. We have earlier showed that a higher number of strains from Japan had an intact cag PAI [7], hence it may be thought as an important factor influencing the outcome of the infection as a higher rate of gastric cancers was observed in the Japanese patients. The possible role of cagA in oncogenic mechanisms is being worked upon [33]. Most English strains in our case retained the cagT and the $\operatorname{cag} \mathrm{E}$ genes. Studies showed that strains lacking the cagT gene had a defective 'molecular syringe' that is encoded by the PAI [34] reflecting thus on inability of the Type IV system to eject out the cagA protein. The cagE gene on the other hand is known to induce NFkB activation and IL8 secretion [8] in addition to mediating host-cell cytokine rearrangements in infected epithelial cells. About $25 \%$ of the strains carried the type IIIa motif on the right end of the cagA gene. This observation also supports the hypothesis that some of the European strains share some features typical of the Asian genogroups. This is also supportive of an earlier observation [31] that a very small number of strains from the European countries also show the type III motif.

English strains mainly showed a higher number of the toxigenic s1 type of vacA allele. Interestingly, the $\mathrm{s} 1 \mathrm{~m} 1$ combination was observed in less percentage in contrast to the $\mathrm{s} 1 \mathrm{~m} 2$ genotype that was seen in $60 \%$ of the cases. Earlier studies in a subset of European population (MidEssex) by RFLP of the mid-region of the vacA gene in strains originating from dyspeptic patients demonstrated that $46 \%$ of these strains had the s $1 \mathrm{~m} 2$ genotype while $40 \%$ strains had the more toxigenic s $1 \mathrm{~m} 1$ combination
[35]. The s1m2 genotype was also common in strains from North Wales among clarithromycin sensitive and resistant $H$. pylori [36]. It was interesting to find the $\mathrm{m} 1 \mathrm{c}$ allele [28], which is known to be prominent in the East Asians, in UK strains. None of the strains had multiple vacA genotypes, which are common in China and other East Asian countries [37]. It has been reported earlier that the $s 1$ allele was most frequently observed in the European population with the s1a allele predominant in Northern and Eastern Europe. Also, s1a and s1b alleles were observed in France and Italy while the Spanish and Portuguese strains had the s1b subtype [13].

The virulence spectrum of the English strains was also exemplified by the observation that $70 \%$ of these strains had the oipA gene in frame. Greater than 6 CT repeats in the upstream homopolymeric tail of the oipA gene is characteristic of European strains [16]. Our results indicate that English strains most commonly displayed 6 CT repeats. Strains with $9 \mathrm{CT}$ repeats were reported to have the gene out of frame owing to the deletion of the CTAA sequence present immediately upstream of the CT repeats [16]. Similar results were found with English strains with 9CT repeats. From our analyses, the iceA1 allele was more common than the iceA2 allele. Although no association between iceA subtypes and clinical outcome has been reported, strains carrying iceA1 produce higher levels of IL- 8 in the gastric mucosa and are more often associated with DU in the North America and Dutch people than strains carrying iceA2 [38]. The plasticity region genes are speculated to provide the strains with survival benefits in some hosts [25]. This region extends from the ORFs JHP914 to JHP951 in the sequenced strain J99 and is shown to be unstable since some genes within the zone are lost during subsequent infections or laboratory passages [25]. It is now evident from partial sequencing of a Peruvian isolate that this plasticity region might encode yet another type IV secretion system [39] and that the 2 sequenced genomes carry incomplete sets of genes corresponding to this cluster. All the English strains we looked at were similar to either strains 26695 and J99 in that none of them harbored a complete plasticity region cluster as shown recently for a Peruvian strain [39] (data not shown). However, any role of such a putative secretory system is still enigmatic due to lack of correlation of its intactness or abrogation with disease, although, some of the ORFs in the plasticity region have been shown to be associated with a particular disease outcome [25,40]. For English strains, we analyzed seven ORFs from the plasticity region cluster, of which HP986 was strain 26695 specific, while others excluding HP912 were J99 specific. The ORF HP912, the predicted cell division protein/septum formation protein ( $f t s \mathrm{~A}$ ) was PCR amplified in $93.5 \%$ strains. JHP931, a predicted DNA topoisomerase I was 
amplified in $51 \%$. None of the strains had the same regions of the plasticity zone deleted.

Our phylogenetic analyses based on the FAFLP markers showed a star like distribution on an unrooted neighborjoining network. Four clusters were evident and the largest cluster was populated mainly by English isolates. Further, affinity to Irish and Indo-European genogroups was also observed. These observations were also substantiated by other slow evolving markers such as ERIC and REP sequences. This denotes stable associations among the genogroups. Similarly, cluster analysis of $b a b \mathrm{~B}$ and $g \operatorname{lmM}$ genes also revealed close associations within the European strains and with the Indian strains. However, homologies with East Asian and Amerindian strains were most noteworthy and were comparable to those shown by Irish strains [41]. This reflects ancient genetic events and possible oriental influences on the evolution of $H$. pylori in the English population. Such kinds of non-random genetic links of $H$. pylori may be helpful in understanding evolution of this organism and its clinical consequences in different parts of the world. These findings are in accordance with a recent study that demonstrated that Indian and European $H$. pylori isolates grouped in the same subpopulation and that East Asian and a subset of European isolates share an ancestral relationship and diverged from each other recently $[27,42]$. The Asian strains, however, were distinctly separated from the European and western strains based on the cagA gene sequences except for a few strains that show remote similarity to the East Asian gene pool. We found only a single English strain (N115) that diverged significantly towards the Asian cluster and was recovered from a patient of Indo-Pakistani origin and thereby denotes contribution from the Asian gene pool.

\section{Conclusion}

In summary, our study demonstrated certain distinctive genetic features of the $H$. pylori gene pool in England based on genotypes of virulence genes and neutral markers. Important among these features is the genetic affinity towards East Asian strains. This is also probably the first comprehensive study on detailed, multilocus and multi method genotyping of $H$. pylori from England or elsewhere. The genomic profiles generated in this study may be useful for electronic archiving and retrieval for interlaboratory comparison and are suitable for storage in epidemiological databases for comparative analyses. However, it will be necessary to analyze additional representative strains, especially from other European populations. Also, our study has largely been an examination of a specific (peptic ulcer disease) group of patient isolates and may not be reflective of other patient isolates from different disease stages in England. Future studies are therefore clearly needed to involve other disease specific strain groups. Further characterization of associations of such informative loci as we examined, in the gene pool of diverse strain groups and with varied disease spectrum may lead to newer insights into the mechanisms of $H$. pylori colonization, and virulence in different hosts.

\section{Methods \\ Bacterial DNA preparations}

Sixty-six DNA preparations using Nacl-CTAB method [43] from English $H$. pylori strains were obtained from the strains corresponding to patients reporting at the Queen's Medical Centre, Nottingham, UK. These strains were recovered from patients diagnosed with ulcer disease, having either current ulceration, past ulceration, evidence of scarring at endoscopy or erosions at endoscopy. More than half of these patients were taking acid suppression therapy. These strains were mainly from ethnic English people, although a few were from people originally from Russia (N90), China (N99), South Asia (N105, N115, N131) and Italy (N106) who had settled in the UK. Strains from other countries were taken from our international collection of genomic DNAs provided by our collaborators. Among these are strains from Spain (HupB, $n$ $=7)$, Ireland (Ire, $\mathrm{n}=14)$, Japan $(\mathrm{Hu}, \mathrm{n}=10)$, Peru (Sjm, $\mathrm{n}=6$ ), Sardinia (Sard, $\mathrm{n}=2$ ), India ( $M S, \mathrm{n}=1 ; \mathrm{L}, \mathrm{n}=10$; BJ, $n=1)$, Bangladesh $(\mathrm{n}=2)$, Holland $(\mathrm{n}=2)$, and $\mathrm{S}$. Africa $(\mathrm{R}, \mathrm{n}=8)$.

\section{Molecular genotyping and sequencing}

Amplification of candidate gene loci including oipA, $b a b \mathrm{~B}$, vacA middle region, cagA and $g l m \mathrm{M}$ genes were carried out as described previously $[44,31,41]$. Purified PCR amplified products (QIAquick Gel extraction kit) were sequenced using the ABI Prism Big Dye Terminator Cycle Sequencing Reaction Kit (Applied Biosystems, Foster City, USA) in an ABI 3100 automated DNA sequencer.

The iceA allele status was determined using oligonucleotide primers mentioned elsewhere [44]. The cag A, cag E and the cag T genes within the cag PAI were detected using 4 pairs of primers as mentioned earlier [7]. Analysis of rearrangements of the motifs at the right end of the cagA gene and towards the 3 ' end of the glutamate racemase gene $(g l r)$ were performed with seven different sets of primers as described previously [31]. PCR primers and procedures used for evaluating the presence of the plasticity region ORFs HP 912, JHP 926, JHP 931, JHP 944, JHP 945, JHP 947 and HP 986 have been described elsewhere [25]. The annealing temperatures for the ORFs HP912, JHP 926 and JHP 944 were standardized to 59, 57 and $66^{\circ} \mathrm{C}$ respectively for $1 \mathrm{~min}$, followed by an extension at $72^{\circ} \mathrm{C}$ for 1 minute.

Consensus sequence for each sample was generated using Genedoc (version 2.6.002). Clustal X (version 1.81) was 
used to align these sequences and dendrograms representing the genetic relationships between strains were generated using Treeview (version 1.6.6). Frame status of the oipA gene was analyzed using Lasergene software (DNAStar Inc. USA). Genetic diversity of the cagA sequences of all the representative isolates tested from English patients were compared to other records from Genbank [China47 (AJ252985), Hong Kong81 (AF198486), Hong Kong77 (AF198485), Japan 54 (AF198484), S. Africa19 (AF198470), Gambia 4659 (AF198468), Gambia4797 (AF198469), Peru24C (AF198473), Peru34B (AY18476), Guatemala88 (AF198472), India18A (AF202224), India19A (AF202225) DH102 (AY169292), DH200 (AY169294), Dutch107 (AJ252963).]. These Genbank sequences were also used along with sequences from English strains for the phylogenetic tree construction.

\section{Whole genomic fingerprinting and genotyping}

Whole genome fingerprinting based on FAFLP genotyping was done as described previously $[43,45]$. Briefly, the profiling of whole genome micro-restriction fingerprints with EcoRI/MseI enzymes using fluorescence tagged primer pairs $E c o R I+A / M s e I+0$ and $E c o R I+G$ or A / MseI+0 was performed. The PCR amplified fragments for each of the strains were then subjected to electrophoretic separation on a $5 \%$ acrylamide gel and scoring of the fluorescent markers was done using an automated DNA analysis workstation (ABI Prism 3100 DNA sequencer).

The PCR methods for the ERIC fingerprinting technique has been previously described [26]. The REP based typing procedure involved primers for amplifying unique DNA sequences between the two REP signatures [46]. All the gel images corresponding to ERIC and REP PCRs were analyzed using the Quantity 1.0 software in a gel documentation system (Bio-Rad, USA). These images were then uploaded into Diversity 2.2.0 database (Bio-Rad, USA). Band sizes, band attributes and standard molecular weights were assigned alongside the molecular weight markers. Cluster analysis of DNA profiles was conducted on the basis of fingerprint characteristics. Based on the data for the presence or absence of 3-15 different DNA fragments in the fingerprints of strains of $H$. pylori, a binary data matrix was created. Overall similarity between the pairs of strains was calculated from the binary data matrix using the simple matching dice coefficient. The resulting similarity matrix was used for cluster analysis by the unweighted paired group method with arithmetic averages (UPGMA) to generate trees.

\section{Data archiving and genome wide comparisons}

All the data obtained through candidate gene sequencing and DNA profiling was deposited in the genoBASE pylori database http://www.cdfd.org.in/amplibase/HP. The genoBASE pylori server was queried for genome wide com- parisons. The cag PAI rearrangement profiles and cag A $g l r$ motif types were also compared to existing records in the database.

\section{Authors' contributions}

FK, MAH and IA did all the PCR based genotyping and sequencing. SS and MD carried out phylogenetic analyses. KRR and AAM provided informatics support and comparative analyses on AmpliBASE server. AAK provided isolates from India and provided some infrastructure support for microbiology work. LAS contributed to the editing of the manuscript and partly supervised the study as a collaborator under the $H$. pylori evolutionary genomics interest group. NA conceived, designed and supervised the study, compiled and edited the manuscript and provided overall supervision and leadership.

\section{Additional material}

\section{Additional file 1}

Summary of genotyping and phylogenetic analyses.

Click here for file

[http://www.biomedcentral.com/content/supplementary/1471-

2180-5-32-S1.doc]

\section{Acknowledgements}

We are thankful to Seyed E. Hasnain, Director of the CDFD for his permission to carry out this study, his keen guidance and encouragement. Our special thanks are due to John Atherton who provided DNA of the English isolates and for critically reading the manuscript. Our thanks are also due to Douglas E. Berg and Asish Mukhopadhyay for their help in articulating this Indo-English collaboration. We are also thankful to our collaborators, especially lan M. Carroll for other DNA samples used in this study. Funding support from the CDFD core grants to NA is gratefully acknowledged. Our special thanks are also due to the International Society for Genomic and Evolutionary Microbiology (ISOGEM) http://www.isogem.org for support. This work was carried out as a collaborative study under the ISOGEM Working Group on Genetics of Helicobacters http://www.pathogen-evolu tion.org.

\section{References}

I. Covacci A, Telford JL, Giudice GD, Parsonnet J, Rappuoli R: Helicobacter pylori virulence and genetic geography. Science 1999, 284: I328-I333.

2. Graham DY, Yamaoka Y: $\boldsymbol{H}$. pylori and cagA relationships with gastric cancer, duodenal ulcer, and reflux esophagitis and its complications. Helicobacter 1998, 3:145-151.

3. Peek RM, Blaser MJ: Helicobacter pylori and gastrointestinal tract adenocarcinomas. Nat Rev Cancer 2002, 2:28-37.

4. Telford JL, Covacci A, Ghiara P, Montecucco C, Rappuoli R: Unravelling the pathogenic role of Helicobacter pylori in peptic ulcer: potential new therapies and vaccines. Trends Biotechnol 1994, 12:420-426.

5. Richter JE, Falk GW, Vaezi MF: Helicobacter pylori and gastroesophageal reflux disease: the bug may not be all bad. $\mathrm{Am} \mathrm{J}$ Gastroenterol 1998, 93:1800-1802.

6. Merrell DS, Falkow S: Frontal and stealth attack strategies in microbial pathogenesis. Nature 2004, 430:250-256.

7. Kauser F, Khan AA, Hussain MA, Carroll IM, Ahmad N, Tiwari S, Shouche Y, Das B, Alam M, Ali SM, Habibullah CM, Sierra R, Megraud 
F, Sechi LA, Ahmed N: The cag pathogenicity island (cag-PAI) of Helicobacter pylori is disrupted in majority of patient isolates from different human populations. J Clin Microbiol 2004, 42:5302-5308.

8. Maeda S, Yoshida H, Ikenoue T, Ogura K, Kanai F, Kato N, Shiratori Y, Omata M: Structure of the cag pathogenicity island in Japanese Helicobacter pylori isolates. Gut 1999, 44:336-34I.

9. Jenks $P$, Megraud $F$, Labigne $A$ : Clinical outcome after infection with Helicobacter pylori does not appear to be reliably predicted by the presence of any of the genes of the cag pathogenicity island. Gut 1998, 3:752-758.

10. Nilsson C, Sille'n A, Eriksson L, Strand ML, Enroth H, Normark S, Falk $P$, Engstrand L: Correlation between cag Pathogenicity Island Composition and Helicobacter pylori-Associated Gastroduodenal Disease. Infection Immun 2003, 7 I:6573-658I.

II. Parsonnet J, Friedman GD, Orentreich N, Vogelman H: Risk for gastric cancer in people with Cag A positive or CagA negative Helicobacter pylori infection. Gut 1997, 40:297-30I.

12. Wirth T, Wang X, Linz B, Novick RP, Lum JK, Blaser M, Morelli G, Falush $D$, Achtman $M$ : Distinguishing human ethnic groups by means of sequences from Helicobacter pylori: Lessons from Ladakh. Proc Natl Acad Sci USA 2004, I0 I:4746-475 I.

13. Fischer W, Gebert B, Haas R: Novel activities of the Helicobacter pylori vacuolating cytotoxin from epithelial cells towards the immune system. Int J Med Microbiol 2004, 293:539-547.

14. Van Doorn LJ, Figueiredo C, Megraud F, Pena S, Midolo P, Queiroz DM, Carneiro F, Vanderborght B, Pegado MD, Sanna R, De Boer W, Schneeberger PM, Correa P, Ng EK, Atherton J, Blaser MJ, Quint WG: Geographic distribution of vacA allelic types of Helicobacter pylori. Gastroenterol 1999, I 1 6:823-830.

15. Atherton JC, Peek RM Jr, Tham KT, Cover TL, Blaser MJ: Clinical and pathological importance of heterogeneity in vacA, the vacuolating cytotoxin gene of Helicobacter pylori. Gastroenterol 1997, I I 2:92-99.

16. Ando T, Peek RM, Pride D, Levine SM, Takata T, Lee YC, Kusugami K, van der Ende A, Kuipers EJ, Kusters JG, Blaser MJ: Polymorphisms of Helicobacter pylori HP0638 Reflect Geographic Origin and Correlate with cagA Status. J Clin Microbiol 2002, 40:239-246.

17. Rad R, Gerhard M, Lang R, Schoniger M, Rosch T, Schepp W, Becker I, Wagner H, Prinz C: The Helicobacter pylori Blood Group Antigen-Binding Adhesin Facilitates Bacterial Colonization and Augments a Nonspecific Immune Response. I Immuno 2002, 168:3033-3041.

18. Zambon CF, Navaglia F, Basso D, Rugge M, Plebani M: Helicobacter pylori babA2, cagA, and s I vacA genes work synergistically in causing intestinal metaplasia. J Clin Pathol 2003, 56:287-29l.

19. van Doorn LJ, Figueiredo C, Sanna R, Plaisier A, Schneeberger P, de Boer W, Quint W: Clinical relevance of the cagA, vacA, and iceA status of Helicobacter pylori. Gastroenterol I998, I I 5:58-66.

20. Gunn MC, Stephens JC, Stewart JD, Rathbone B]: Detection and typing of the virulence determinants cagA and vacA of Helicobacter pylori directly from biopsy DNA: are in vitro strains representative of in vivo strains? Eur J Gastroenterol Hepatol 1998, 10:683-687.

21. van der Ende A, Pan ZJ, Bart A, van der Hulst RW, Feller M, Xiao SD, Tytgat GN, Dankert J: cagA-Positive Helicobacter pylori Populations in China and The Netherlands Are Distinct. Infect Immun 1998, 66:1822-1826.

22. Hiroto M, Mae FG, Nobuhiro S: $\boldsymbol{H}$. pylori and Gastric cancer: the Asian Enigma. Am J Gastroenterol 2002, 97: I I06-III 2.

23. Population statistics of UK available at the URL [http://
[ www.statistics.gov.uk/cci/nugget.asp?id=764]

24. Vyse AJ, Gay N], Hesketh LM, Andrews N], Marshall B, Thomas HI, Morgan-Capner P, Miller E: The burden of Helicobacter pylori infection in England and Wales. Epidemiol Infect 2002, 128:411 -4I7.

25. Occhialini A, Marais A, Alm R, Akanuma M, Mitsuno Y, Imai Y, Yoshida $\mathrm{H}$, Shiratori $\mathrm{Y}$, Omata M: Distribution of open reading frames of plasticity region of strain $\mathbf{9 9}$ in Helicobacter pylori strains isolated from gastric carcinoma and gastritis patients in Costa Rica. Infect Immun 2000, 68:6240-6249.

26. Hussain MA, Kauser F, Khan AA, Tiwari S, Habibullah CM, Ahmed N Implicationsof Molecular Genotyping of Helicobacter pylori Isolates from Different Human Populations by Genomic Fingerprinting of Enterobacterial Repetitive Intergenic Consen- sus Regions for Strain Identification and Geographic Evolution. J Clin Microbiol 2004, 42:2372-2378.

27. Ghose C, Perez-Perez GI, Bello MGD, Pride DT, Bravi CM, Blaser MJ: East Asian genotypes of Helicobacter pylori strains in Amerindians provide evidence for its ancient human carriage. Proc Natl Acad Sci USA 2002, 99:15107-15।II.

28. Mukhopadhyay AK, Kersulyte D, Jeong JY, Datta S, Ito Y, Chowdhury A, Chowdhury S, Santra A, Bhattacharya SK, Azuma T, Nair GB, Berg DE: Distinctiveness of genotypes of Helicobacter pylori in $\mathrm{Cal}-$ cutta, India. J Bacteriol 2000, I 82:32 I 9-3227.

29. Pride DT, Meinersmann RJ, Blaser MJ: Allelic Variation within Helicobacter pylori babA and babB. Infect Immun 200I, 69: II60-II7I.

30. Solnick JV, Hansen LM, Salama NR, Boonjakuakul JK, Syvanen M: Modification of Helicobacter pylori outer membrane protein expression during experimental infection of rhesus macaques. Proc Natl Acad Sci USA 2004, I01:2106-2III.

3I. Kersulyte D, Mukhopadhyay AK, Velapatino B, Su W, Pan Z, Garcia C, Hernandez V, Valdez Y, Mistry RS, Gilman RH, Yuan Y, Gao H, Alarcon T, Lopez-Brea M, Balakrish Nair G, Chowdhury A, Datta S, Shirai M, Nakazawa T, Ally R, Segal I, Wong BC, Lam SK, Olfat FO, Boren T, Engstrand L, Torres O, Schneider R, Thomas JE, Czinn S, Berg DE: Differences in genotypes of Helicobacter pylori from different human populations. J Bacteriol 2000, 182:3210-32/8.

32. History of migrations in Europe hosted at the website [http:/ [www.let.leidenuniv.nl/history/migration/chapter | |3.html]

33. Hatakiyama M: Oncogenic mechanisms of Helicobacter pylori cagA protein. Nature Rev Cancer 2004, 4:688-694.

34. Rohde M, Puls J, Buhrdorf R, Fischer W, Haas R: A novel sheathed surface organelle of the Helicobacter pylori Cag type IV secretion system. Mol Microbiol 2003, 49:219-234.

35. Owen RJ, Xerry J, Peters TM, Teare EL: Surveillance and clinical relevance of vacA genotypes of Helicobacter pylori infecting dyspeptic patients in mid-Essex. Commun Dis Public Health 2002, 5:I06-III.

36. Elviss NC, Owen RJ, Xerry J, Walker AM, Davies K: Helicobacter pylori antibiotic resistance patterns and genotypes in adult dyspeptic patients from a regional population in North Wales. J Antimicrob Chemother 2004, 54:435-440.

37. Smith SI, Kirsch C, Oyedeji KS, Arigbabu AO, Coker AO, Bayerdoffer E, Miehlke S: Prevalence of Helicobacter pylori vacA, cagA and iceA genotypes in Nigerian patients with duodenal ulcer disease. J Med 2002, 5 I:85 I-854.

38. Xu Q, Martin JB: Promoters of the CATG-Specific Methyltransferase Gene hpyIM Differ between iceAl and iceA2 Helicobacter pylori Strains. J Bacteriol 200I, I 83:3875-3884.

39. Kersulyte D, Velapatino B, Mukhopadhyay AK, Cahuayme L, Bussalleu A, Combe J, Gilman RH, Berg DE: Cluster of type IV secretion genes in Helicobacter pylori's plasticity zone. J Bacteriol 2003, 185:3764-3772.

40. Paul JJ, Benjamin A, Christos A0: Strain specific genes of Helicobacter pylori : distribution, function and dynamics. Nucliec Acids Res 200I, 29:4395-4404.

4I. Carroll IM, Ahmed N, Beesley SM, Khan AA, Ghousunnissa S, Morain CA, Habibullah CM, Smyth CJ: Microevolution between paired antral and paired antrum and corpus Helicobacter pylori isolates recovered from individual patients. J Med Microbiol 2004, 53:669-677.

42. Falush D, Wirth T, Linz B, Pritchard JK, Stephens M, Kidd M, Blaser MJ, Graham DY, Vacher S, Perez-Perez GI, Yamaoka Y, Megraud F, Otto K, Reichard U, Katzowitsch E, Wang X, Achtman M, Suerbaum $\mathrm{S}$ : Traces of human migrations in Helicobacter pylori populations. Science 2003, 299: $1582-1585$

43. Ahmed N, Khan AA, Alvi A, Tiwari S, Jyothirmayee CS, Kauser F, Al M, Habibullah CM: Genomic analysis of Helicobacter pylori from Andhra Pradesh, South India: Molecular evidence for three major genetic clusters. Curr Sci 2003, 85: $101-108$.

44. Kauser F, Hussain MA, Ahmed I, Ahmad N, Habeeb A, Khan AA, Ahmed N: Comparing Genomes of Helicobacter pylori Strains from the High-Altitude Desert of Ladakh, India. J Clin Microbiol 2005, 43: 1538-1545.

45. Carroll IM, Ahmed N, Beesley SM, Khan AA, Ghousunnissa S, O'Morain CA, Smyth CJ: Fine- structure molecular typing of Irish Helicobacter pylori isolates and their genetic relatedness to strains from four different continents. I Clin Microbiol 2003, 41:5755-5759. 
46. Versalovic J, Koeuth T, Lupski JR: Distribution of repetitive DNA sequences in Eubacteria and application to fingerprinting of bacterial genomes. Nucleic Acid Res 1991, 19:6823-6831.

Publish with Bio Med Central and every scientist can read your work free of charge

"BioMed Central will be the most significant development for disseminating the results of biomedical research in our lifetime. " Sir Paul Nurse, Cancer Research UK

Your research papers will be:

- available free of charge to the entire biomedical community

- peer reviewed and published immediately upon acceptance

- cited in PubMed and archived on PubMed Central

- yours - you keep the copyright

Submit your manuscript here:

http://www.biomedcentral.com/info/publishing_adv.asp
BioMedcentral 